\section{Software for screening to assess risk of Down's syndrome}

SIR, - The brief reference to screening for Down's syndrome in the $\mathrm{ABC}$ of antenatal care' is perhaps indicative of the few centres currently offering screening to assess the risk of Down's syndrome despite the considerable benefits that the screen offers. The delays in introducing the screen are possibly due to uncertainty about the analytes required to perform an effective screen. $\alpha$ Fetoprotein and human chorionic gonadotrophin are well established, but there is still dispute over whether unconjugated oestriol should be included. ${ }^{23}$ Furthermore, other potential screening variables have been suggested, including pregnancy specific $\beta_{1}$ glycoprotein (SP-1), ${ }^{4}$ ratio of biparietal diameter to length of femur, ${ }^{5}$ and maternal urea resistant neutrophil alkaline phosphatase activity. ${ }^{6}$

A further cause of delay in introducing the screen is the poor availability of commercial software to calculate the risk. In Gwent and South Glamorgan screening using $\alpha$ fetoprotein and human chorionic gonadotrophin has been offered with considerable success for the past 16 months Introduction of this service was possible only after in house software had been developed. ${ }^{7}$ Therefore, to encourage the spread of screening throughout the United Kingdom an MS-DOS compatible software package written in Turbo-PASCAL for one off calculation of risks of Down's syndrome is available from us free of charge to the NHS, and the complete database software used to run the Gwent screening program is also available subject to a small Foxbase licensing charge (details from me). A simple program will also be accessible by modem on the Association of Clinical Biochemists' bulletin board in the next few weeks (details from Dr J Kay, clinical biochemistry department, John Radcliffe Hospital, Oxford).

T M REYNOLDS

Medical Biochemistry Department,

University Hospital of Wales

Cardiff CF4 4 XW

1 Chamberlain G. ABC of antenatal care: normal antenatal management. BMF 1991;302:774-9. (30 March.)

Wald N, Cuckle H, Densem J, et al. Maternal serum screening for Down's syndrome in early pregnancy. BMF 1988;297: 883-7.

3 Macri J, Kasturi R, Krantz D, Cook E, Sunderii S, Larsen J. Maternal serum Down syndrome screening: unconjugate estriol is not useful. Am $\mathcal{F}$ Obstet Gynecol 1990;162:672-3.

4 Bartels I, Lindemann A. Maternal levels of pregnancy-specific $\beta_{1}$ glycoprotein (SP-1) are elevated in pregnancies affected by $\beta_{1}$ glycoprotein (SP-1) are elevated in pregnanci

5 O'Brien W, Knuppel R, Torres C, Sternlicht D. Potential prenatal predictors of Down syndrome: a statistical analysis. prenatal predictors of Down syndrom

6 Cuckle H, Wald N, Goodburn S, Sneddon J, Amess J, Dunn S Measurement of activity of urea resistant neutrophil alkaline phosphatase as an antenatal screening test for Down' syndrome. BMf 1990;301:1024-6.

7 Reynolds T, Penney $M$. The mathematical basis of multivariat risk screening: with special reference to screening for Down's syndrome associated pregnancy. Ann Clin Biochem 1990;29: $452-8$.

\section{Estimations of gestational age and screening for Down's syndrome}

SIR,-Professor Roger Robinson notes that increased use of the "triple" screening test for Down's syndrome may result in a reduction in the number of children born with the syndrome. Despite considerable interest in the triple test, our experience is that obstetricians are not generally aware of the importance of accurate estimation of gestational age.

Using an equation derived from the results of Wald $e t a l^{2}$ we calculated the risk of Down's syndrome at term for 3532 patients in our data base. We calculated the likelihood ratio assuming the gestation to be $15 \cdot 0,16 \cdot 0,17 \cdot 0$, and $18 \cdot 0$ weeks.
Effect on risk of Down's syndrome at term of underestimation of gestation. All results are expressed as ratio of likelihood ratio at $16.0,17.0$ or 18.0 weeks to the likelihood ratio at $15 \cdot 0$ weeks

\begin{tabular}{lrrr}
\hline & \multicolumn{3}{c}{ Assumed gestation (weeks) } \\
\cline { 2 - 4 } & 16.0 & 17.0 & 18.0 \\
\hline Arithmetic mean & 2.96 & 7.98 & 17.32 \\
Geometric mean & 2.64 & 6.26 & 12.52 \\
Median & 2.64 & 6.43 & 12.99 \\
Standard deviation & 1.56 & 6.42 & 15.62 \\
5th centile & 1.43 & 1.98 & 2.90 \\
95th centile & 5.72 & 15.06 & 35.64 \\
\hline
\end{tabular}

The likelihood ratio was then expressed as a ratio to that at 15.0 weeks. The table shows the results

Many centres use ultrasonography to screen for neural tube defects at 18 weeks and do not have the resources to scan at 15 weeks as well. Screening for Down's syndrome is best performed at 15.0 weeks as this is the earliest gestation for which the screen has been validated. ${ }^{2}$ This results in requests for calculation of risk of Down's syndrome based on gestation by last normal menstrual period at about 15 weeks.

Commercial software packages currently available calculate a single risk based on one estimated gestation. Estimation of gestation by last normal menstrual period in women who are sure of their dates results in an error of more than two weeks in $17 \%$ of women. ${ }^{3}$ The $95 \%$ confidence limit for estimation of gestation by measurement of biparietal diameter by ultrasonography up to 20 weeks is about one week.

Recalculation of risk may be necessary in about $15 \%$ of patients. We would be unable to recalculate the risk for $15 \%$ of the 5000 patients to whom we offer this screen each year.

We therefore report a risk for five different gestations: that quoted on the request form and also assuming a gestation of $15 \cdot 0,16 \cdot 0,17 \cdot 0$, and 18.0 weeks. In a woman of uncertain gestation, reporting a range of risks within which the pregnancy falls may provide useful information when amniocentesis is being considered. Disadvantage are the complicated nature of the report produced and providing technical back up for our inhouse software. Our system also requires specialist knowledge about screening for Down's syndrome which is not essential when commercial software packages are used. This format of reporting highlights the need to use the best available assessment of length of gestation.

S HOLDING

Pathology Department,

Kingston General Hospital

Hull HU3 IUR

1 Robinson R. Fewer neural tube defects: more Down's. $B M \mathcal{J}$ 1991;302:612. (16 March.)

2 Wald NJ, Cuckle HS, Demsem JW, et al. Maternal serum creening for Down's syndrome in early pregnancy. $B M$ 1988;297:883-7.

3 Bennett MJ, Little G, Dewhurst J, Chamberlain G. Predictive value of ultrasound measurements in early pregnancy: randomised controlled trial. Br f Obstet Gynaecol 1982;89. random $338-41$.

4 Bowie JD, Andreotti RF. Estimating gestational age in utero. In

Callen PW, ed. Ultrasonography in obstetrics and gynecology. Philadelphia: Saunders, 1983:21-40.

\section{Work can damage your health}

SIR,-David McIntosh has suggested that ethical guidelines for occupational physicians should be revised to reduce the risk that doctors' duty to the employer will prevent them speaking out when a warning could help prevent accidents and illnesses.'

The Faculty of Occupational Medicine's guidance on ethics for occupational physicians, which has established itself as a reliable reference document, covers a wide range of problems that may be encountered by a doctor working in , industry. It deals specifically with the relationship between the doctor and the employer and emphasises doctors' duty to individual patients and the independence of their position in clinical matters. Doctors may be employed by a particular organisation but they have an ethical duty to put their patients' interests first. The faculty has formulated a clause for inclusion in the contract of employment of an occupational physician spelling out the distinction between responsibility to an employer and ethical obligations. Where problems still remain the guidelines suggest discussion and consultation with appropriate senior colleagues.

Our experience suggests that the faculty's guidance on ethics deals adequately with problems of this kind should they arise. Furthermore, under the Health and Safety at Work Act 1974 (section $2(2) c$ and section 6) the duties of an employer in these circumstances are also clear.

R I MCCALLUM

Faculty of Occupational Medicine,

Royal College of Physicians,

London NW1 4LE

1 Dyer C. Work can damage your health. BMF 1991;302:433-4 23 February.

2 Faculty of Occupational Medicine, Royal College of Physicians of London. Guidance on ethics for occupational physicians. 3rd ed. London: RCP, 1986

\section{The new culture}

SIR, - A big variable in service provision is the referral rates from general practitioners to outpatient departments. The auditors from the National Audit Office seemed unsure whether a high rate of referral or a low rate represented the best practice. Some comfort is taken about this because for the first time general practitioners have to submit information in annual reports, which will include their referral practices, which Mr John Warden says "can be challenged."

However, I would challenge the whole matter of the referral rates reported in practice reports. Schedule 1E, referring to Regulation 3(2) of Terms of Service for Doctors in General Practice, refers to "the referral of patients to other services under the National Health Service Act 1977."' In the leafy lanes of most cities many - if not most-referrals are now to private units outside the NHS which do not have to be included in general practitioners' annual reports. The danger is that the referral rates in well off practices will seem to be much lower than in the inner city practices where patients are entirely reliant on the provision of the NHS. If the National Audit Office wants a valid comparison of referral rates between practices then it has to compare like with like. Hence a valid comparison means the total referrals whether in the NHS or outside it. Under general practitioners' present terms of service, referrals outside the NHS will not be included and it will not, therefore, be possible to compare like with like for referral rates.

JOHN D SINSON

Leeds LS17 6HF

1 Warden J. The new culture. BMf 1991;302:554. (9 March.)

\section{Global warming and health}

SIR, - Professor Andrew Haines's editorial conveys the impression that adverse effects of global warming would dominate.' All countries except equatorial countries show higher mortality in winter than summer. The table shows large increases in mortality in winter in Mediterranean countries, where protection against cold is often less good than in Britain. Heat related mortality is real, but comparatively minor; so are possible effects of the spread of tropical diseases, which are in any case largely controllable. The data on seasonal mortality clearly suggest that the direct effect of moderate global warming on mortality, at 